Jurnal Instruksional, Volume 1, Nomor 2, April $2020 \mid 152$ ISSN: $2686-5645$

\title{
PENGARUH METODE PEMBELAJARAN DAN GAYA BELAJAR TERHADAP HASIL BELAJAR IPA
}

\author{
${ }^{1}$ Ika Yuwanita, ${ }^{2}$ Happy Indira Dewi, ${ }^{3}$ Dirgantara Wicaksono \\ ${ }^{1}$ SD Negeri Joglo 09 \\ email: ika_olv@yahoo.co.id \\ ${ }^{2}$ Magister Teknologi Pendidikan, Universitas Muhammadiyah Jakarta \\ email: h.indiradewi@umj.ac.id \\ ${ }^{3}$ Magister Teknologi Pendidikan, Universitas Muhammadiyah Jakarta \\ email: dirgantarawicaksono@umj.ac.id
}

\begin{abstract}
This research aims to know the influence of the method of learning and learning style against the results of the Study IPA. This research uses experimental methods with quantitative research design treatmen by level 2x2. The instruments used to study results of multiple choice tests and is used for visual learning style is the questionnaire. The results of this study indicate that: (1) student learning outcomes given Expository learning methods in higher Learning of students who are granted for Conventional learning methods Learning (2) there is the influence of the interaction between the learning methods and visual learning style (3) the results of the study and science students who have high visual learning style and learning methods given expository learning higher than students who were given conventional learning methods learning (4) the results of the study and science students who have low visual learning style and learning methods given expository learning lower than students who were given conventional learning methods learning.
\end{abstract}

Keywords: results learn IPA, learning methods, visual learning style

\begin{abstract}
Abstrak
Penelitian bertujuan untuk mengetahui pengaruh metode pembelajaran dan gaya belajar terhadap hasil belajar IPA siswa. Penelitian menggunakan penelitian kuantitatif dengan metode eksperimen desain treatmen by level $2 \times 2$. Instrumen yang digunakan untuk hasil belajar adalah tes pilihan ganda dan yang digunakan untuk gaya belajar visual adalah kuesioner. Hasil penelitian ini menunjukkan bahwa : (1) hasil belajar siswa yang diberikan metode pembelajaran Expository Learning lebih tinggi dari siswa yang diberikan metode pembelajaran Conventional Learning (2) terdapat pengaruh interaksi antara Metode pembelajaran dan gaya belajar visual (3) Hasil Belajar IPA siswa yang memiliki gaya belajar visual tinggi dan diberikan metode pembelajaran Expository Learning lebih tinggi dari siswa yang diberikan metode pembelajaran Conventional Learning (4) Hasil Belajar IPA siswa yang memiliki gaya belajar visual rendah dan diberikan metode pembelajaran Expository Learning lebih rendah dari siswa yang diberikan metode pembelajaran Conventional Learning.
\end{abstract}

Kata kunci: hasil belajar IPA, metode pembelajaran, gaya belajar visual

\section{PENDAHULUAN}

Pendidikan merupakan salah satu bidang yang sangat diprioritaskan dalam pembangunan nasional dan mewujudkan cita-cita untuk mencerdaskan kehidupan bangsa. Tersedianya tenaga-tenaga kerja yang terampil dan terdidik sebagai syarat penting berlangsungnya pembangunan ekonomi secara berkesinambungan dapat terpenuhi. Hal ini menunjukkan bahwa pendidikan memiliki pengaruh yang kuat dan positif terhadap pembangunan ekonomi. Dalam kegiatan belajar atau pembelajaran terjadi interaksi yang bertujuan. Interaksi yang bertujuan disebabkan guru memaknai belajar atau pembelajaran dengan menciptakan lingkungan yang bernilai edukatif demi 
kepentingan siswa. Hal ini sejalan dengan pendapat Miarso (2011: 528) bahwa pembelajaran atau kegiatan instruksional adalah usaha mengelola lingkungan dengan sengaja agar seseorang membentuk diri secara positif dalam kondisi tertentu. Ini berarti pembelajaran terkait dengan pendayagunaan lingkungan belajar sedemikian rupa sehingga dapat membuat siswa belajar.

Mata pelajaran ilmu pengetahuan alam (IPA) merupakan ilmu yang mempelajari tentang fenomena alam dan segala sesuatu yang ada di alam, dengan ruang lingkupnya meliputi makhluk hidup, energi dan perubahannya, bumi dan alam semesta serta proses materi dan sifatnya. Peran IPA yang penting dalam kemajuan suatu bangsa, mengakibatkan pendidikan IPA perlu diperkenalkan, diajarkan dan dikembangkan sedini mungkin pada generasi muda terutama siswa SD/MI yang umumnya pada usia mereka rasa keingintahuannya cenderung lebih tinggi.

Sementara pengamatan (observasi) pendahuluan di kelas menunjukkan bahwa pembelajaran IPA masih menggunakan pendekatan/strategi konvesional atau directed learning/direct instruction. Guru Iebih banyak menggunakan metode ceramah dan tanya-jawab dengan sumber utama buku sekolah elektronik (BSE) yang didownload dari website Kementerian Pendidikan dan Kebudayaan. Adapun waktu pembelajaran IPA di kelas kurang dan separuh digunakan siswa untuk mengerjakan tugas dan latihan soal dan BSE. Guru jarang sekali menugaskan siswa untuk mencari materi mata pelajaran IPA secara online sebagai bahan untuk memperdatam teori-teori atau konsep-konsep tentang mata pelajaran IPA.

Dengan demikian, apakah terdapat perbedaan hasil belajar IPA siswa yang menggunakan metode pembelajaran expository learning dibandingkan dengan siswa yang menggunakan metode pembelajaran conventional learning? Jika ada perbedaan, kelompok manakah yang memperoleh hasil belajar lebih tinggi?

\section{KAJIAN LITERATUR Hasil Belajar IPA}

Gredler (2009: 2) mengatakan: "learning is a multifaceted process that individuals typically take for granted until they experience difficulty with a complex task". Gredler mendefinisikan belajar sebagai proses seseorang memperoleh berbagai kecakapan, keterampilan, dan sikap. Sementara itu, Mayer (2011: 250-252) mengatakan "Learning is seen as a process of reinforcing knowledge acquired in a sequenced and hierarchical fashion and learning tasks can be preplanned, organized, and programmed with specific outcomes defined." Disini Mayer mengatakan bahwa belajar dipandang sebagai suatu proses memperkuat pengetahuan yang diperoleh dalam mode sequencing dan hirarkis dan tugas belajar dapat direncanakan, terorganisir, dan diprogram dengan hasil spesifik yang dapat didefinisikan.

Gagne membagi hasil (1977: 26-28) belajar menjadi lima kategori yaitu keterampilan intelektual (intellectual skills), strategi kognitif (cognitive strategies), informasi verbal (verbal information), keterampilan motorik (motor skills), dan sikap (attitudes).

\section{Pengertian IPA}

Pembelajaran

IPA sebaiknya dilaksanakan secara inkuiri iImiah (scientific inquiry) untuk menumbuhkan kemampuan berpikir, bekerja dan bersikap ilmiah serta mengkomunikasikannya sebagai aspek penting kecakapan hidup. Aspek penting yang harus diperhatikan guru dalam pelaksanaan pembelajaran IPA di SD adalah melibatkan siswa secara aktif dalam pembelajaran untuk mengembangkan kemampuan berpikirnya.

Guru IPA harus memberikan kesempatan bagi peserta didik untuk 
berdiskusi dari berbagai bentuk kerja sama halnya untuk menyelesaikan tugas yang diberikan. Di dalam pembelajaran IPA, peserta didik didorong untuk belajar melalui keterlibatan aktif dengan keterampilanketerampilan, konsep-konsep, dan prinsipprinsip. Menurut Djamarah (2002: 14) hasil belajar adalah "perubahan yang terjadi sebagai akibat dari kegiatan belajar yang telah dilakukan oleh individu". Teori Gestalt, menguraikan bahwa pembelajaran merupakan usaha guru untuk memberikan materi pembelajaran sedemikian rupa, sehingga siswa lebih mudah mengorganisirnya (mengaturnya) menjadi suatu gestalt (pola bermakna).

\section{Metode Pembelajaran}

Suyono dan Hariyanto (2011: 18) mengungkapkan istilah metode, pendekatan, teknik, dan strategi belajar dan pembelajaran sering digunakan secara bergantian walaupun pada dasarnya mempunyai perbedaan.

\section{Metode Expository Learning}

Dimyati (2009: 172) dalam bukunya Belajar dan Pembelajaran, menyatakan prilaku mengajar dengan strategi expository juga dinamakan model ekspositori, pembelajaran yang menekankan kepada proses penyampaian materi secara langsung dari seorang guru kepada siswanya dengan maksud agar siswa dapat menguasai materi pembelajaran secara optimal.

Tujuan utama dalam pembelajaran expository learning adalah "memindahkan" pengetahuan, keterampilan, dan nilai-nilai kepada siswa. Metode pembelajaran expository learning lebih menekankan kepada proses bertutur, maka sering juga dinamakan strategi "chalk and talk". Dalam metode pembelajaran expository learning, guru sangat dominan memegang peranan dalam pembelajaran. Melalui pendekatan ini guru menyampaikan materi pembelajaran secara terstruktur dengan harapan materi yang disampaikan dapat dikuasai siswa dengan baik.

\section{Metode Conventional Learning}

Djamarah (2001: 97), metode pembelajaran konvensional adalah metode pembelajaran tradisional atau disebut juga dengan metode ceramah, karena sejak dulu metode ini telah dipergunakan sebagai alat komunikasi lisan antara guru dengan anak didik dalam proses belajar dan pembelajaran. Secara umum, ciri-ciri pembelajaran konvensional adalah:

(1) siswa adalah penerima informasi secara pasif, dimana siswa menerima pengetahuan dari guru dan pengetahuan diasumsinya sebagai badan dari informasi dan keterampilan yang dimiliki sesuai dengan standar.

(2) Belajar secara individual

(3) Pembelajaran sangat abstrak dan teoritis

(4) Perilaku dibangun atas kebiasaan

(5) Kebenaran bersifat absolut dan pengetahuan bersifat final

(6) Guru adalah penentu jalannya proses pembelajaran

(7) Perilaku baik berdasarkan motivasi ekstrinsik

(8) Interaksi di antara siswa kurang

(9) Guru sering bertindak memperhatikan proses kelompok yang terjadi dalam kelompok-kelompok belajar.

\section{Gaya Belajar}

Keanekaragaman cara siswa dalam belajar disebut dengan gaya belajar, ada pula yang menyebutnya dengan modalitas belajar. Pengetahuan tentang gaya belajar siswa sangat penting untuk diketahui guru, orang tua, dan siswa itu sendiri karena pengetahuan tentang gaya belajar ini dapat digunakan untuk membantu memaksimalkan proses pembelajaran agar hasil pembelajaran dapat tercapai sesuai dengan tujuan yang diharapkan.

Bob Samples (2002: 146) gaya belajar adalah kebiasaan yang mencerminkan cara 
memperlakukan pengalaman dan informasi yang kita peroleh. Setiap individu memunyai gaya belajar yang berbeda. Tidak semua orang mengikuti cara yang sama. Masingmasing menunjukkan perbedaan, namun para peneliti dapat menggolonggolongkannya. Mulyono (2012: 226-228) gaya belajar berkaitan erat dengan pribadi seseorang, yang dipengaruhi oleh pembawaan, pengalaman, pendidikan, dan riwayat perkembangannya. Gaya belajar yang dimaksud dalam penelitian ini adalah cara yang digunakan oleh siswa dalam menyerap informasi atau materi pelajaran berdasarkan pendekatan preferensi sensori. Yaitu gaya belajar yang dilakukan dengan cara memasukkan informasi ke dalam otak melalui modalitas indera yang dimiliki.

\section{Gaya Belajar Visual}

DePorter dan Hernacki (lihat hal 71: 113) dalam buku Quantum Learning menuliskan bahwa gaya belajar visual merupakan belajar dengan cara melihat, yaitu gaya belajar yang menggunakan indera penglihatan sebagai modal utama dalam menyerap dan mengingat informasi. Siswa dengan gaya belajar visual cenderung lebih cepat menyerap informasi dengan melihat bagaimana guru menerangkan materi belajar di depan kelas dengan alat bantu berupa data maupun gambar. Sementara Alan Pritchard (2009: 44) mengatakan bahwa pelajar visual lebih menyukai belajar dengan cara melihat. Mereka memiliki ingatan visual yang baik dan lebih memilih informasi disajikan secara visual dalam bentuk diagram, grafik, peta dan poster.

DePorter dan Hernacki (2003: 116) individu dengan gaya belajar visual mempunyai ciri-ciri sebagai berikut: (1) rapi dan teratur, (2) berbicara dengan cepat, (3) perencana dan pengatur jangka panjang yang baik, (4) teliti terhadap detail, (5) mementingkan penampilan, baik dalam hal berpakaian maupun presentasi, (6) pengeja yang baik dan dapat melihat kata-kata yang sebenarnya dalam pikiran mereka, (7) mengingat apa yang dilihat, daripada yang didengar, (8) mengingat dengan asosiasi visual, (9) biasanya tidak terganggu oleh keributan, (10) pembaca cepat dan tekun, (11) lebih suka membaca daripada dibacakan, (12) suka mencoret-coret tanpa arti, (13) lupa menyampaikan pesan verbal kepada orang lain, (14) sering menjawab pertanyaan dengan jawaban singkat "ya" atau "tidak", (15) lebih suka melakukan demonstrasi daripada pidato, dan (16) Iebih suka seni daripada musik.

\section{METODE PENELITIAN}

Penelitian ini menggunakan metode quasi eksperimen dengan desain treatment by level 2x2. Menurut Creswell (2015: 159) desain factorial yaitu suatu variasi antara desain kelompok yang terdiri dari dua atau lebih variabel perlakuan untuk menguji variabel bebas dan efek simultan pada variabel perlakuan pada suatu hasil outcome Populasi penelitian ini adalah siswa kelas IV SD Negeri Joglo 09 Jakarta sedangkan sampel pada penelitian ini adalah kelas IV B sebagai kelas experimen dan kelas IV D sebagai kelas kontrol. Teknik pengambilan sampel dilakukan secara random sampling.

Variabel penelitian terdiri dari satu variabel terikat yaitu hasil belajar IPA dan dua variabel bebas yaitu metode pembelajar sebagai variabel perlakuan serta gaya belajar sebagai variabel atribut. Variabel metode pembelajaran terdiri dari metode expository learning dan conventional learning, sedangkan variabel gaya belajar terdiri dari gaya belajar visual tinggi dan rendah.

Kuesioner keefektifan penerapan metode pembelajaran ekspository learning dalam penelitian ini terdiri dari 10 pertanyaan obyektif dengan menggunakan skala Likert (rentang 1-5). Sedangkan lembar soal hasil belajar (posttest) terdiri dari soal-soal yang mengacu pada Taksonomi Bloom yang berupa enam rana kognitif antara lain: (1) C1: mengingat, (2) 
C2: memahami, (3) C3: mengaplikasikan, (4) C4: menganalisis, (5) C5: mengevaluasi, (6) C6: mencipta.

Data kuesioner dianalisis dengan menggunakan rating scale. Data penelitian berupa tes dianalisis secara deskriptif dan uji-t. Analisis deskriptif digunakan untuk mendeskripsikan rata-rata nilai tes dari kedua kelas dan membandingkan nilai ratarata kelas. Sebelum dilakukan pengujian hipotesis terlebih dahulu dilakukan uji normalitas dengan menggunakan Liliefors, sedangkan uji homogenitas varian antar kelompok menggunakan levene test. Semua uji tersebut menggunakan bantuan software SPSS versi 17.0 dan dilakukan pada taraf signifikansi 0,05 . Pengujian hipotesis menggunakan teknik analisis varians dua jalur (ANAVA) desain treatmen by level $2 \times 2$.

\section{HASIL DAN PEMBAHASAN Pengujian Hipotesis}

Anava dua jalur (twoway anova) bertujuan mengetahui :

1. Pengaruh utama (Main Effect) yaitu pengaruh metode pembelajaran terhadap hasil belajar IPA atau apakah terdapat perbedaan skor hasil belajar IPA siswa pada kelompok yang diajar dengan metode pembelajaran yang berbeda, metode pembelajaran yang digunakan dalam penelitian ini adalah metode pembelajaran expository learning (A1) dan metode pembelajaran conventional learning (A2), untuk mengetahui signikan atau tidaknya perbedaan yang ada dilakukan dengan uji $\mathrm{F}$, dengan kriteria pengujian Fhitung $>$ F Tabel, maka dapat disimpulkan perbedaan hasil belajar antara kelompok A1 da Kelompok A2 adalah signifikan.

2. Pengaruh interaksi (Interaction effect) yaitu mencari perbedaan Skor hasil belajar IPA pada siswa yang belajar dengan metode pembelajaran yang berbeda (Expository dan Conventional) dan memilki perbedaan dalam gaya belajar visual (Tinggi dan Rendah), untuk mengetahui signikan atau tidaknya pengaruh interaksi yang ada dilakukan dengan uji $\mathrm{F}$, dengan kriteria pengujian Fhitung $>$ F Tabel.

3. Pengaruh Sederhana (Simple Effect) yaitu mencari pengaruh metode pembelajaran yang digunakan pada kelompok dengan Gaya Belajar Visual yang sama.

Simple effect 1): Mengetahui perbedaan rata-rata hasil belajar IPA antara yang menggunakan metode pembelajaran Expository Learning dan metode pembelajaran Conventional Learning pada kelompok siswa dengan gaya belajar visual tinggi. Untuk mengetahui signikan atau tidaknya perbedaan yang ada pada kelompok (A1B1 x A2B1) dilakukan dengan uji Tuckey, dengan kriteria pengujian p-Value $($ Sig) < alpha $(0,05)$, maka dapat disimpulkan perbedaan hasil belajar antara kelompok (A1B1 x A2B1) adalah signifikan.

Simple effect 2): Mengetahui perbedaan rata-rata hasil belajar IPA antara yang menggunakan metode pembelajaran expository learning dan metode pembelajaran conventional learning pada kelompok siswa dengan gaya belajar visual rendah. Untuk mengetahui signikan atau tidaknya perbedaan yang ada pada kelompok (A1B1 x A2B1) dilakukan dengan uji Tuckey, dengan kriteria pengujian p-Value (Sig) < alpha $(0,05)$, maka dapat disimpulkan perbedaan hasil belajar antara kelompok (A1B1 x A2B1) adalah signifikan.

\section{Pembahasan Hasil Penelitian}

1. Terdapat perbedaan hasil belajar IPA antara siswa yang belajar dengan Metode Pembelajaran Expository Learning dan Metode Pembelajaran Conventional Learning (A1 dan A2). Dalam penelitian telah ditemukan bahwa terdapat perbedaan yang signifikan hasil belajar 
IPA antra siswa yang belajar dengan metode pembelajaran expository learning dengan siswa yang belajar menggunakan metode pembelajaran conventional learning. Hasil belajar IPA pada siswa yang memiliki metode pembelajaran expository learning lebih tinggi dibandingkan siswa yang menggunakan metode pembelajaran conventional learning.

2. Pengaruh interaksi Metode Pembelajaran dan Gaya Belajar Visual terhadap hasil belajar IPA (AXB) Besar pengaruh interaksi antara metode pembelajaran dan gaya belajar visual terhadap hasil belajar IPA adalah $66,00 \%$ (R.Squared $=0,660$ ) ini berarti hasil belajar IPA ditentukan oleh metode pembelajaran dan gaya belajar visual sebesar $66,00 \%$. Hasil penelitian pada pengujian hipotesis menunjukkan terdapat pengaruh interaksi antara metode pembelajaran (metode pembelajaran expository learning dan metode pembelajaran conventional learning) dan memiliki gaya belajar visual terhadap hasil belajar IPA.

3. Siswa dengan Gaya Belajar Visual Tinggi, memiliki hasil belajar IPA lebih baik bila dengan Metode Pembelajaran Expository Learning. Skor hasil belajar IPA siswa yang belajar dengan metode pembelajaran expository learning dengan gaya belajar visual tinggi (A1B1) adalah 87,78 sedangkan skor rata-rata skor hasil belajar IPA yang belajar dengan metode pembelajaran conventional learning dengan gaya belajar visual tinggi (A2B1) adalah 52,22 dan Uji Tuckey menunjukkan perbedaan rata-rata skor sebesar 35,56 dan nilai p-value ( $\mathrm{Sig}$ ) sebesar $0,000(0,000<0,05)$. Hal ini menunjukkan terdapat perbedaan yang signifikan hasil belajar IPA siswa yang belajar dengan metode pembelajaran expository learning dan metode pembelajaran conventional learning pada siswa dengan gaya belajar visual tinggi.

4. Siswa dengan Gaya Belajar Visual Rendah, hasil belajar IPA lebih baik pada siswa yang menggunakan Metode Pembelajaran Conventional Learning (A1B2 dan A2B2). Skor rata-rata hasil belajar IPA yang belajar dengan metode pembelajaran expository learning dengan gaya belajar visual rendah (A1B2) adalah 60,00 sedangkan skor rata-rata hasil belajar IPA yang belajar dengan metode pembelajaran conventional learning dengan gaya belajar visual rendah (A2B2) adalah 77,78 dan $\mathrm{Uji}$ Tuckey menunjukkan perbedaan rata-rata skor sebesar 17,78 dan nilai $p$-value (Sig) sebesar 0,007 $(0,007<0,05)$. Hal ini menunjukkan terdapat perbedaan signifikan hasil belajar IPA siswa yang belajar dengan metode pembelajaran expository learning dan metode pembelajaran conventional learning pada siswa dengan gaya belajar visual rendah.

\section{KESIMPULAN}

Metode pembelajaran expository learning cocok digunakan dalam pembelajaran IPA karena dapat meningkatkan hasil belajar IPA. Upaya untuk meningkatkan hasil belajar IPA, guru perlu memperhatikan tingkat gaya belajar visual dan membagi kelompok siswa yang memiliki gaya belajar visual tinggi dan rendah kemudian menentukan metode pembelajaran yang tepat. Siswa yang memiliki gaya belajar visual tinggi lebih sesuai jika diberikan metode pembelajaran expository learning. Siswa yang memiliki gaya belajar visual rendah lebih sesuai jika diberikan metode pembelajaran conventional learning. Saran yang dapat diajukan dalam penelitian ini adalah sebagai berikut :

1. Guru disarankan menggunakan metode pembelajaran expository learning untuk dapat memicu siswa mengembangkan gaya belajar visual dalam menguasai 
materi pelajaran dan meningkatkan hasil belajar IPA siswa kelas IV SD Negeri Joglo 09 Jakarta Barat.

2. Guru sebaiknya mempertimbangkan karakteristik siswa khususnya tingkat gaya belajar visual sehingga guru dapat memilih metode pembelajaran yang tepat dalam pembelajaran.

3. Siswa mempunyai tingkat gaya belajar visual yang berbeda dalam mengikuti kegiatan pembelajaran IPA. Guru disarankan memberikan metode pembelajaran expository learning kepada siswa yang memiliki gaya belajar visual tinggi dan metode pembelajaran conventional learning kepada siswa dengan gaya belajar visual rendah untuk meningkatkan hasil belajar IPA.

4. Guru mata pelajaran IPA sangat perlu peningkatan kompetensi dalam hal pengelolaan pembelajaran dan penguasaan materi. Metode pembelajaran expository learning memberikan dampak yang signifikan pada hasil belajar IPA. Mengingat guru perlu menambah wawasan tentang metode pembelajaran maka disarankan kepada kepala sekolah agar memfasilitasi guru mata pelajaran IPA dengan pelatihan tentang penerapan metode pembelajaran expository learning.

\section{REFERENSI}

Creswell, John. 2015. Riset Pendidikan: Perencanaan, Pelaksanaan, dan Evaluasi Riset Kualitatif dan Kuantitatif, edisi kelima. Yogyakarta: Pustaka Pelajar.

DePorter, Bobbi dan Mike Hernacki. 2003. Quantum Learning: Membiasakan Belajar Nyaman dan Menyenangkan, terjemahan Alwiyah Abdurahman. Bandung: Kaifa.
Dimyati dan Mudjiono. 2009. Belajar dan Pembelajaran. Jakarta: Rineka Cipta.

Djamarah, Syaiful Bahri. 2002. Psikologi Belajar. Jakarta: PT Rineka Cipta.

Gagne, Robert M., 1977. The Conditions of Learning. New York: Holt, Rinehart and Winston.

Gredler, Margareth E. 2009. Learning and Instruction: Theory into Practice, sixth edition. New Jersey, Ohio: Pearson Education Inc.

Mayer, Richard E. dan Patricia A. Alexander. 2011. Handbook of Research on Learning and Instruction: Educational Phychology Handbook Series. New York: Routledge.

Mulyono. 2012. Strategi Pembelajaran. Malang: UIN-Maliki Press.

Samples, Bob. 2002. Revolusi Belajar untuk Anak: Panduan Belajar sambil Bermain untuk Membuka Pikiran Anak-anak Anda, terj. Rahmani Astuti. Bandung: Kaifa.

Slameto. 2003. Belajar dan Faktor-Faktor yang Mempengaruhinya. Jakarta: PT. Rineka Cipta.

Suyono dan Hariyanto. 2011. Belajar dan Pembelajaran: Teori dan Konsep Dasar. Bandung: PT Remaja Rosdakarya.

Pritchard, Alan. 2009. Ways of Learning; Learning Teorities and Learning Styles in the Classroom. New York: Madison Avenue.

Yusufhadi, Miarso. 2011. Menyemai Benih Teknologi Pendidikan. Jakarta: Kencana Prenada Media Group 